\title{
Water Conservation and Smart Agriculture in India
}

\author{
Raghav Bansal
}

Department of Information Technology, Maharaja Agrasen Institute of Technology, PSP Area, Rohini Sector 22, Delhi, India

\section{To Cite this Article}

Raghav Bansal, "Water Conservation and Smart Agriculture in India", International Journal for Modern Trends in Science and Technology, 6(12): 315-318, 2020.

\section{Article Info}

Received on 10-November-2020, Revised on 02-December-2020, Accepted on 06-December-2020, Published on 14-December-2020.

\section{ABSTRACT}

In India about 70\% of population depends upon farming and one third of the nation's capital comes from agriculture. Water is one of the most important components used in agriculture. Water is one of the most fundamental resources required in agriculture. Flooding the field is one of the most common practices of soil irrigation used in India, even though options like sprinklers, drip irrigation, and others are available. These issues concerning agriculture have been always hindering the development of the country. The only solution to this problem is smart agriculture, in essence, by modernizing the current traditional methods of agriculture, it is possible to help develop the nation and society as a whole. Hence, the project aims at making the practice of agriculture smart by using automation and IoT technologies.

KEYWORDS: IoT, automation, Wi-Fi

\section{INTRODUCTION}

Agriculture is the main source of livelihood for over $58 \%$ of the country's population. It is a major contributor towards the nation's economy. Besides providing employment opportunities to numerous sections of the society, agriculture can also be termed as the backbone of our nation's growth. It is quite evident now, how the growth of agricultural sector is necessary for the economic development of the country. Unfortunately, in India, the condition of farmers is not very good. Unlike a farmer in the west, who works like an entrepreneur by employing modern technologies, farmers in India generally utilize traditional methods of farming and work like peasants.

Now, coming to the impending water crisis faced by the nation. In India, approximately $80 \%$ of the entire water available is used for irrigation purposes, which is magnanimous as compared to the $12 \%$ used by Industrial and $4 \%$ used by the domestic sector. [1] It should be noted that a majority amount of water used in irrigation is actually wasted, since techniques such as flooding the fields are common. This paper aims to reduce this wastage of water by providing a solution that is feasible and can be implemented on a large scale to cut down the wastage of water.

The paper aims at making agriculture in India smarter by implementing Internet of Things and automation. The highlight of this paper is the smart irrigation system which works on integrated moisture sensors with smart control based on real time field data. These sensors get the data in real time and control the flow of water so as to ensure that there is minimal wastage and the crop yield remains either unaffected or increases. Controlling of these operations will be through a web application or a mobile application on any device or computer connected to the Internet and the operations will be performed by interfacing sensors, Wi-Fi or Bolt IoT modules.

\section{RELATED WORK}

The current scenario depicts ever decreasing water tables, drying rivers, ponds, lakes, tanks, along with unpredictable environmental issues and 
calamities that present an urgent need of conservation of water. To cope up with this, moisture and temperature sensors can be used at suitable locations for monitoring the field and crops. [2] The technological development in Wireless Sensor Networks has made it possible to use this form of technology in monitoring and control of greenhouse parameters in agriculture. [3]

In the following studies related to wireless and sensor networking, researchers have measured soil related parameters such as temperature and humidity. In these models, sensors were placed below the soil which communicated the data by means of relay nodes using effective communication protocol providing low duty cycle; thereby increasing the life expectancy of soil monitoring system. [4]

\section{SYSTEM OVERVIEW}

The paper consists of three sections; module 1 (Moisture Sensor Module), module 2 (Bolt IoT Module), and PC or mobile app to control the irrigation system. The mode of operation can be auto or manual. In auto mode system takes its own decisions by getting the data directly from the sensors and controls the installed devices whereas in manual mode the user can control the system using android app or PC commands.

The proposed model can be further furnished with additional functionalities to check $\mathrm{Ph}$, temperature, and other relevant parameters to ensure plant growth and increment in the yield.

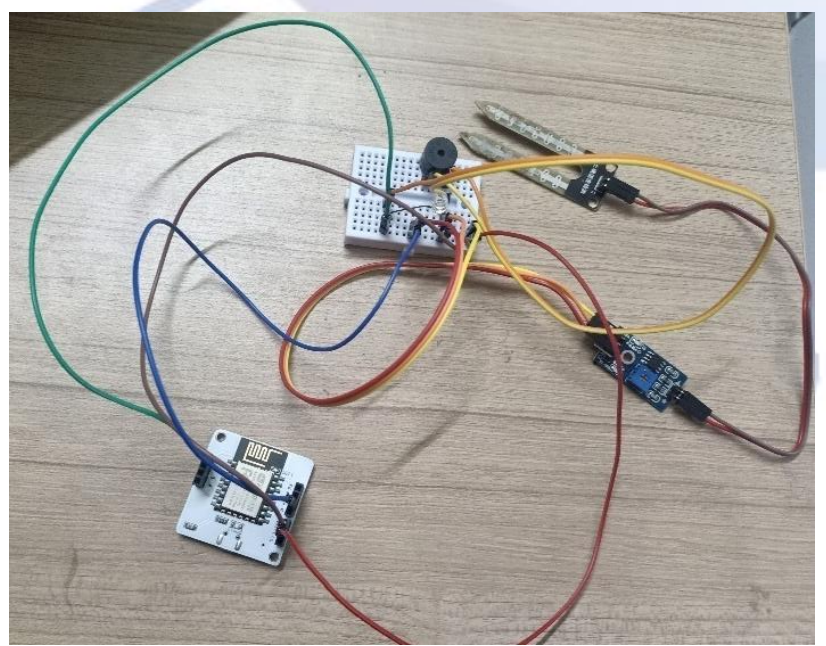

Figure 1. System Overview

\section{ARCHITECTURE OF THE SYSTEM}

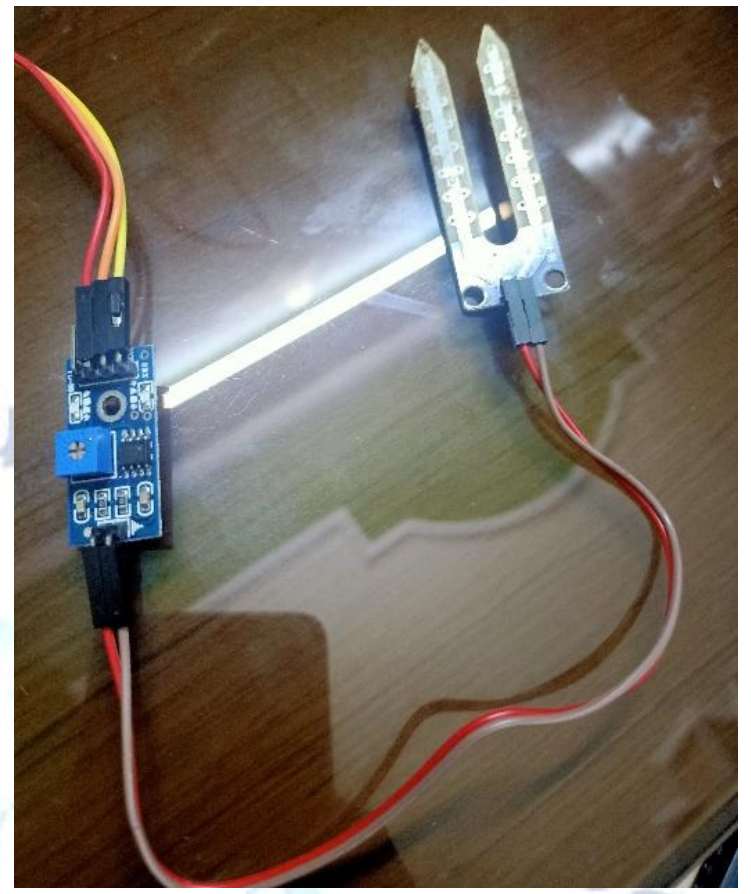

Figure 2: Module 1

Module 1:

Module 1 or the Moisture Sensor Module comprises of a sensor, wires and integrated circuit. Which is used to collect the data in analog form and send it to Bolt IoT module.

The moisture sensor module primarily consists of four pins, namely VCC, A0, DO, and GND. VCC and GND pins are connected to the power input and ground respectively.

\section{Module 2:}

Module 2 or the Bolt IoT Module is used to connect the entire circuit and compile the project. It comprises of various pins and ports which are connected to different components that make up the circuit.

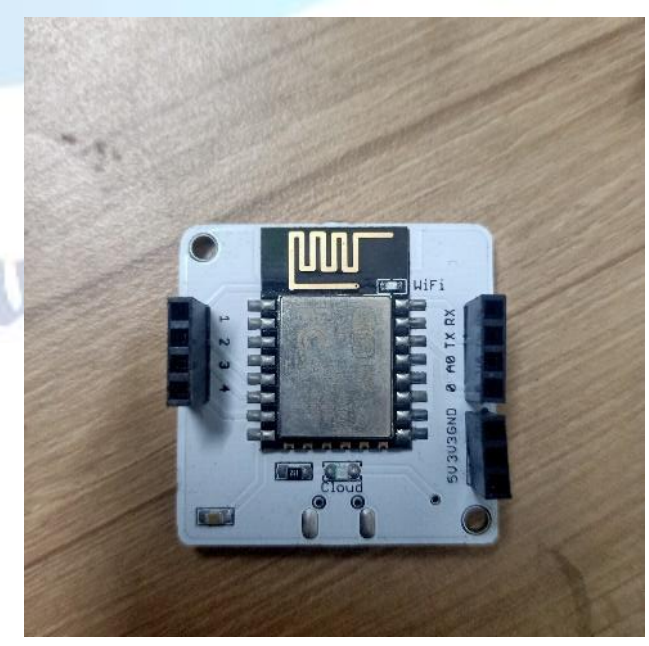

Figure 3: Module 2(a) 


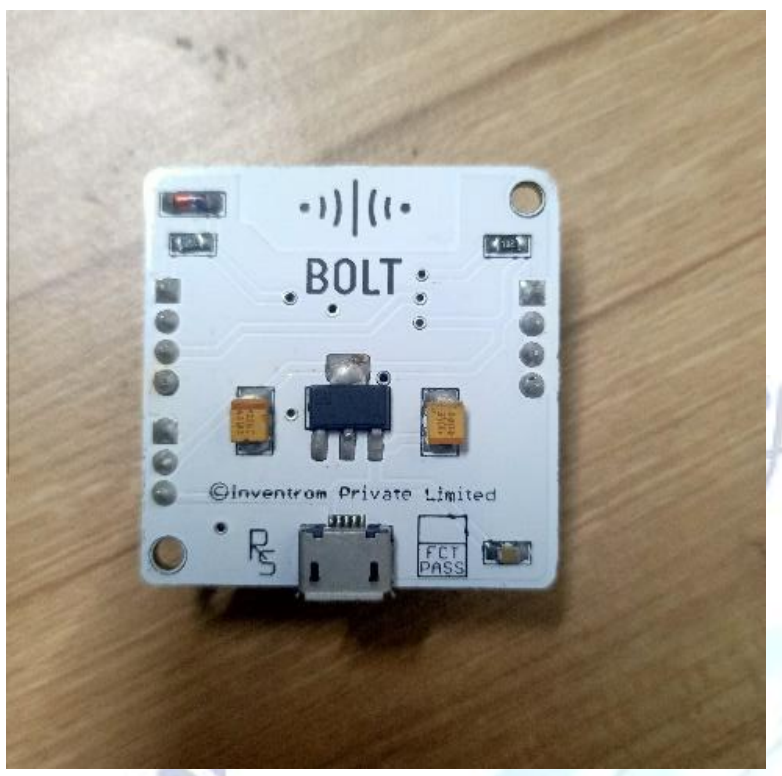

Figure 4: Module 2(b)

Hardware used:

a) Bolt IoT Module

b) Moisture sensor module

c) Connecting Wires

d) LED/Buzzer (Output device)

e) Other parameter modules (Optional)

f) Mobile / PC / Laptop (Compatible with all)

Software used:
a) Bolt IoT Configuration Platform
b) HTML
c) JavaScript
d) Cascading Style Sheets

\section{EXPERIMENT AND RESULTS}

As shown in figure 1 , the experimental setup for the project consists of both the modules inclusive of the moisture sensor. The sensors have been successfully interfaced with the Bolt IoT microcontroller which in turn is interfaced with web application that controls the system.

Test results show that higher the value obtained from the system, lower is the amount of moisture in the soil. Thus, establishing an inverse relationship between the soil moisture content and the numeric value obtained via the sensor. It was observed that whenever the input value was lower than the preset standard value, the system alerted that ample moisture content was available in the soil. In case the input value exceeded the standard value, an alert was issued that stated that amount of moisture present in the soil was less and water flow was initiated. In this case, the LED turned on, thus completing the implementation of the project.

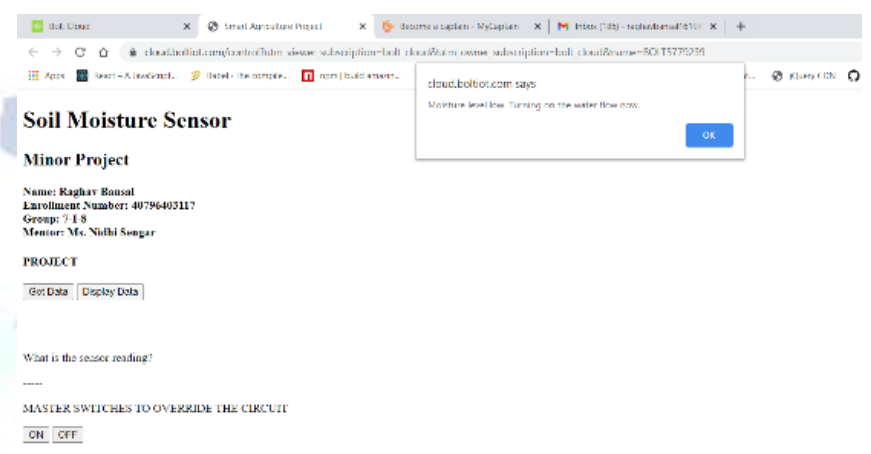

Figure 5: Low Moisture Alert

The master switches given in the figure 5 are used to override the system in case of an anomaly or emergency, thus acting as a failsafe.

The entire system is fairly simple and can be used by even the illiterate as no extra or technical knowledge is required. Such a system can easily be implemented on a national or even a global level to improve the lifestyle of the farmers as well as the condition of water levels and water tables, especially in India.

The proposed system was tested in various environments using multiple soil samples of varying moisture levels. The proposed system worked efficiently and showed correct results in all of the cases. In some cases, the time taken was slightly more than the other cases, but the end result was that the system worked fluently and gave perfect results, albeit delayed.

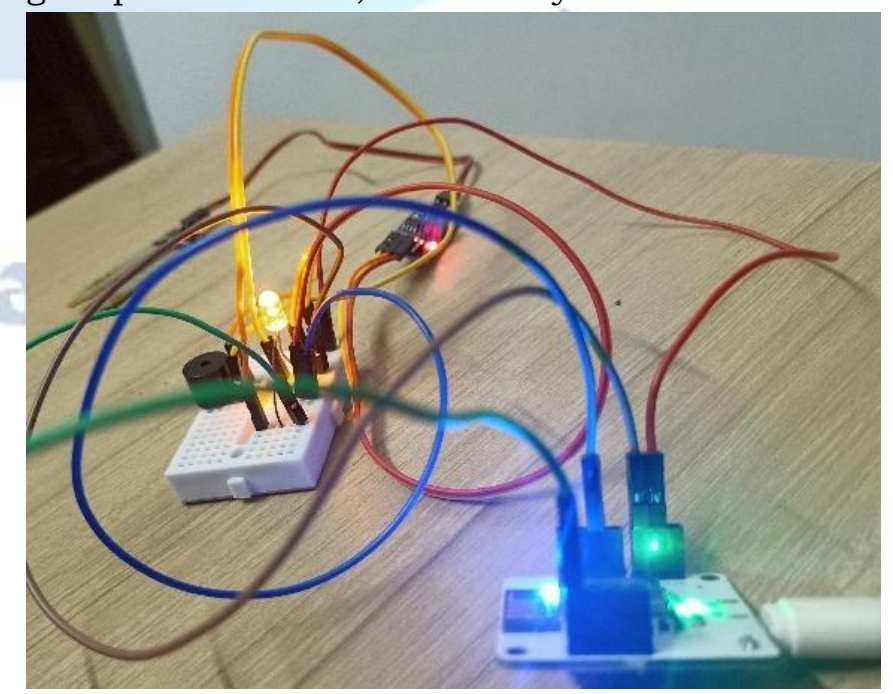

Figure 6: Module LED On 


\section{Vi. Conclusion}

The sensor of moisture sensor module was successfully interfaced with Bolt IoT Module and wireless communication is achieved between various modules.

At present approximately 40,000 Million Litres of water is used per day in India for agriculture. [6] The proposed model is fit to be implemented on a large scale with minor modifications. Implementation of such a system in the field can definitely help to conserve water and cut down the usage of water by at least half.

\section{ACKNOWLEDGMENT}

I would like to thank all my professors, guides and mentors for their unconditional support and guidance that made this project possible.

\section{REFERENCES}

[1] Dr. Vibha Dhawan "Water and Agriculture in India" 2017. OAV - German Asia-Pacific Business Association within the frame of the Bilateral Cooperation Project on the Development of International Cooperation with Asia, co-funded by the Federail Ministry of Food and Agriculture (BMEL)

[2] S. R. Nandurkar, V. R. Thool, R. C. Thool, "Design andDevelopment of Precision Agriculture System Using Wireless Sensor Network", IEEE International Conference on Automation, Control, Energy and Systems (ACES), 2014

[3] Dr. V .Vidya Devi,G. Meena Kumari, "Real- Time Automation and Monitoring System for Modernized Agriculture” ,International Journal of Review and Research in Applied Sciences and Engineering (IJRRASE) Vol3 No.1. PP 7-12, 2013

[4] Q. Wang, A. Terzis and A. Szalay, "A Novel Soil Measuring Wireless Sensor Network", IEEE Transactions on Instrumentation and Measurement, pp. 412-415, 2010

[5] Yoo, S.; Kim, J.; Kim, T.; Ahn, S.; Sung, J.; Kim, D. A2S: Automated agriculture system based on WSN. In ISCE 2007. IEEE International Symposium on Consumer Electronics, 2007, Irving,TX, USA, 2007

[6] https://www.orfonline.org/expert-speak/if-80-water-cons umption-in-india-is-for-agriculture-why-is-it-unregulatedand-inefficient/\#: :text=This\%20amounts\%20to\%20aroun d\%2040\%2C000,and $\% 20$ waste $\% 20$ water $\% 20$ contains $\% 20$ nutrients.
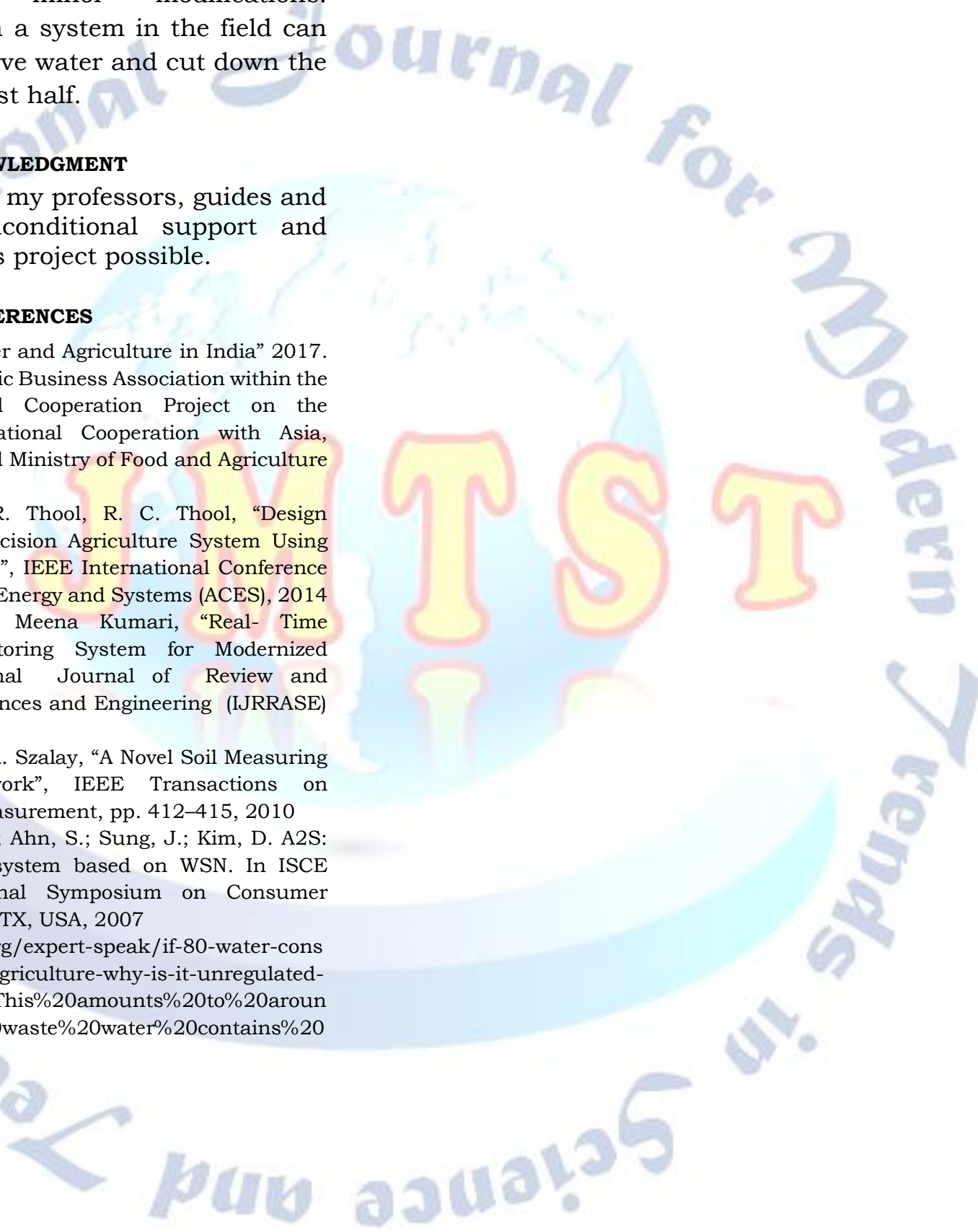